\title{
Game feature and expertise effects on experienced richness, control and engagement in game play
}

\author{
Marco C. Rozendaal · David V. Keyson · \\ Huib de Ridder $\cdot$ Peter O. Craig
}

Received: 16 March 2008/Accepted: 12 December 2008/Published online: 3 March 2009

(C) The Author(s) 2009. This article is published with open access at Springerlink.com

\begin{abstract}
The extent to which game play is experienced as engaging is an important criterion for the playability of video games. This study investigates how video games can be designed towards increased levels of experienced engagement over time. For this purpose, two experiments were conducted in which a total of 35 participants repeatedly played a video game. Results indicate that experienced engagement is based on the extent to which the game provides rich experiences as well as by the extent to which the game provides a sense of control. In view of the influence of both game features and players' expertise on the levels of experienced richness and control, it is concluded that game features should be modified over time to maintain optimal levels of engagement.
\end{abstract}

\footnotetext{
M. C. Rozendaal ( $\square)$

Designing Quality in Interaction, Department of Industrial

Design, Eindhoven University of Technology, Eindhoven,

The Netherlands

e-mail: m.c.rozendaal@tue.nl

URL: http://www.tue.nl/staff/m.c.rozendaal

D. V. Keyson

Social and Contextual Interaction Design,

Department of Industrial Design, Delft University

of Technology, Delft, The Netherlands

e-mail: d.keyson@io.tudelft.nl

URL: http://studiolab.io.tudelft.nl/scid/

H. de Ridder · P. O. Craig

Human Information and Communication Design,

Department of Industrial Design, Delft University

of Technology, Delft, The Netherlands

H. de Ridder

e-mail: h.deridder@tudelft.nl

URL: http://www.io.tudelft.nl

P. O. Craig

e-mail: craigproductions@gmail.com
}

\section{Introduction}

Knowledge about engagement as a key element in gaming is of increasing interest since "...over the last three decades, gaming has gradually become one of the main entertainment media, comparable in revenue, customers and employees to the film and music industries..." (Kirriemuir 2002). Engagement is considered a good indicator of game playability (Douglas and Hargadon 2001; Järvinen et al. 2002; Lindley 2004). However, to support the design of engaging video games, more knowledge is needed of the constituents of the experience of engagement and on the game features that promote it. Further, the use of formal models in the design and evaluation of video games is considered increasingly important (Grünvogel 2005; Klabbers 2006). Models are able to make explicit the success factors across a variety of games as well as players' subjective experiences that are important in play. Models may be useful since general guidelines can be developed supporting game design, but can be used as 'user models' embedded within game intelligence (Bradshaw 1997; Keyson 2008). Based on such models, games may autonomously transform themselves in order to maintain optimal levels of game play.

Engagement is a widely used concept that is difficult to grasp because of the many different meanings attributed to it (Hornbæk 2006). In the literature on interaction design, engagement is described as an exciting and enjoyable state of mind in which attention is willingly given and held (Malone 1981; Laurel 1991; Webster et al. 1993; Jacques et al. 1995; Chapman et al. 1999), and was also specifically discussed in relation to web applications (Chen et al. 1999; Novak et al. 2000) and interactive training simulations (Garris et al. 2002). In studies on well-being, engagement has also been described as an optimal state of mind, called 
Flow, in which people report experiencing a sense of enjoyment, losing the sense of self and time, and experiencing effortlessness in the development of skills (Csikszentmihalyi 1990; Ellis et al. 1994). A common factor in these views on engagement is that engaging activities are intrinsically motivating, i.e., the activity is performed for the rewards experienced in optimal human functioning and development (Rogers 1951; Maslow 1970; Deci and Ryan 2000).

In the present article, the focus is on creating engagement in games by taking into account the experienced richness of the game and the extent to which players feel in control of the game (van Reekum et al. 2004). While experienced richness captures the complexities experienced during interaction (Fiske and Maddi 1961), experienced control captures the extent to which goals can be attained (Skinner 1996; Ajzen 2002). Richness promotes engagement because of the association of richness with the excitement experienced when perceiving potentials to develop human faculties, thereby enticing players into play (Webster and Ho 1997). Control promotes engagement because of the association of control with the confidence experienced when these potentials are actualized (White 1959; Hedman and Sharafi 2004). For engagement, both richness and control need to be optimized; a lack of either richness or control results in decreased levels of boredom or anxiety, respectively. This approach is therefore similar to the Flow construct, with the difference that richness and control are somewhat broader definitions compared with challenge and skill (Fiske and Maddi 1961; Novak et al. 2000). In the current study, both game features and players' expertise are considered to affect engagement through experienced richness and control.

Increasing the number of game features is considered to increase levels of experienced richness. Features of interactive systems, including video games, can involve aspects related to function, manipulation and appearance (Barfield et al. 1994). Increasing the number of game functions, for instance, is considered to affect richness at a mental level. Players may choose from alternatives and investigate how game functions are interrelated, thereby promoting discovery (Manninen 2002; Björk et al. 2003). Increasing the degrees of freedom in which a game can be manipulated is considered to increase richness at a behavioral level (Ullmer and Ishii 2000) affecting the physicality of interaction (Djajadiningrat et al. 2004) and promoting challenge when these rich behaviors are involved in goal attainment (Malone 1981). Increasing the amount of media within the appearance of a game is considered to affect richness at a sensorial level (Sutcliffe 2002). Increasing the amount of visual forms, colors and sounds affects vividness, thereby increasing the immersive character of a game (Steuer 1992). Enriching games in these ways therefore engages players by providing new experiences that allow them to develop skills and knowledge.

Increasing the number of game features can simultaneously affect the sense of control that players experience while playing. Averill's (1973) division of decisional, behavioral and cognitive control was found to be a useful construct here. Decisional control was defined by Averill as the "...range of choice or number of options open to a individual" (p. 298). Increasing the number of game functions can increase decisional control since players can choose which goals to pursue. However, decisional control may also decrease if the number of possibilities is increased too far. Players may feel uncertain about whether the right choice has been made given the alternatives (Schwartz 2000). Behavioral control was defined as the control experienced during "direct action on the environment" (p. 286). Increasing the degrees of freedom in game manipulation can decrease behavioral control because of the increased difficulty of the motor coordination needed to perform the required actions, thereby decreasing the effectiveness of action (Skinner 1996). Cognitive control is concerned with the "interpretation of events" (p. 286), and involves information as a key concept. The appearance of a game may affect cognitive control since it provides information for play. Increasing the amount of media within the appearance of a game may increase cognitive control if media redundancy is used to accentuate meaningful information for play, but may decrease cognitive control if media redundancy distracts players from play unnecessarily (Pirhonen 1998). Increasing the number of game features can therefore either support or undermine players' sense of control.

Game features can also effect engagement at a social level. Sociality and engagement have been researched in interaction design (Gaver 1996), learning environments (Kreijns et al. 2007) and virtual environments (Ludvigsen 2006). Here, the authors emphasize the social interactions that interactive systems can mediate through social affordances (Hodges and Baron 2007). Interactive systems affording teamwork, cooperation and competition can be rewarding activities because of the associated experiences of camaraderie and social connectedness (Stangor 2004). These experiences are strong motivators potentially facilitating engagement (Klastrup 2003; Volet and Wosnitza 2004). A previous study investigated how sociality relates to engagement through experienced richness and control by distributing physical game control across players (Rozendaal et al. 2008a). Both richness and control appeared to have a social dimension. Richness related to the extent to which game features allowed varied social interactions arising when game features allowed players to pursue individual and shared goals simultaneously. Control related to the extent to which players could adopt a leading 
role, imposing individual goals on others, or by the extent to which players adopted a conforming role, maintaining effective cooperation towards shared goals. Both physical game features and the players' social adaptation of these features therefore affected experienced engagement.

Players' expertise is thought to interact with game features affecting the levels of experienced richness and control. Expertise is seen as the knowledge a person has about a particular domain and the extent to which a person can act within this domain in a skillful manner (Dreyfus et al. 1986). VanDeventer and White (2002) addressed some of the differences between expert and novice players. Expert players group objects and actions that are involved in a game into larger meaningful patterns, thereby decreasing cognitive load, and their behavior can be characterized as fast and accurate. Due to this grouping, a game may be experienced as less complex, and therefore less rich. At the same time, the levels of experienced control may increase due to the players' ability to attune to the relevant information directly and to elicit appropriate behavioral responses automatically (Rasmussen 1983). For example, once the functional features of a game have been discovered due to increased expertise, the richness of a game may decrease but control may increase as players learn to choose the most appropriate functions for the task at hand. Similarly, as the challenges afforded by the manipulation features of a game are mastered, richness may decrease but control may increase since players can perform the required actions more effectively; possibly bringing about new challenges in the game.

In this study, two experiments were conducted to investigate the effect of game features and players' expertise on experienced engagement through experienced richness and control. The first experiment investigated how increasing the number of game features influences the levels of experienced richness. The second experiment examined how videogames varying in levels of experienced richness affect experienced control and engagement over time. By varying the games over time, the influence of the players' expertise on the levels of experienced control and engagement could be assessed.

\section{Experiment 1}

The goal of this experiment is to assess the extent to which the number of game features leads to experiences of richness.

\subsection{Method}

\subsubsection{Prototype}

A video game was developed in which the number of features could be systematically varied. The game resembled a classic arcade game that could be played on a desktop computer. A virtual aircraft avatar could interact within a virtual game world and points could be earned by performing a variety of actions such as shooting objects and collecting items. Four distinct game strategies were designed: (A) Aircraft control, addressing the physical aspects of play and with the emphasis on game manipulation; (B) Tile coloring and (C) Item collecting, both addressing the mental aspects of play with the emphasis on game functions; and (D) Multiplay, addressing the social aspects of play with the emphasis on control distribution across players. Sensorial aspects of play were not addressed by any one specific game strategy, but varied as a result of the four strategies referred to above; each strategy added visual objects and/or sounds to the appearance of the game. The video game was designed in such a way that game strategies could be freely combined. In addition, each game strategy could be set at three levels of complexity. The number of game features therefore ranged from 1 to a maximum of 12 (Fig. 1). Each game strategy is explained in more detail below.

- Aircraft control involved the possibility of manipulating the aircraft avatar using the keys on a physical keyboard. The perceptual motor coordination required to control the aircraft increased with the complexity. At the first level of complexity, the number of maneuvers that the aircraft could perform involved discrete leftright-up-down movements. At the second level of complexity, the aircraft could perform continuous
Fig. 1 Image of the video game with one feature (left) and 12 features (right)
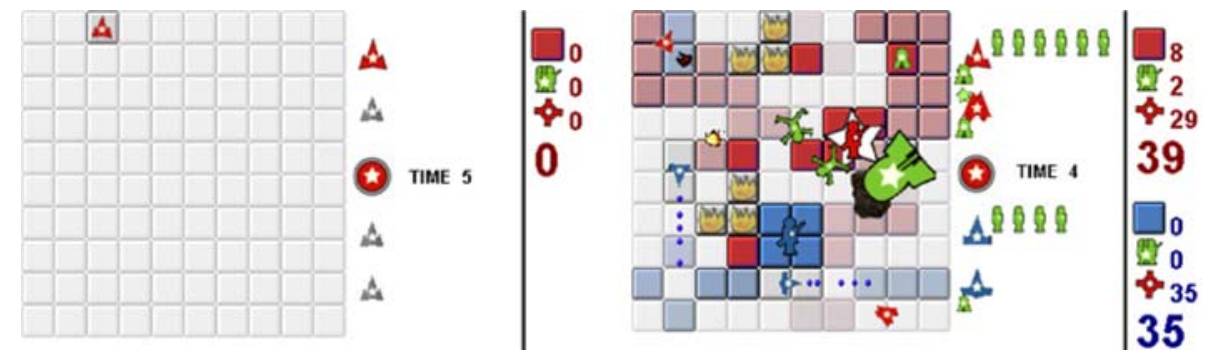
Fig. 2 Image of aircraft control. Aircraft control relies on a visual representation of an aircraft (left) that can be manipulated using the keys on the keyboard (right)
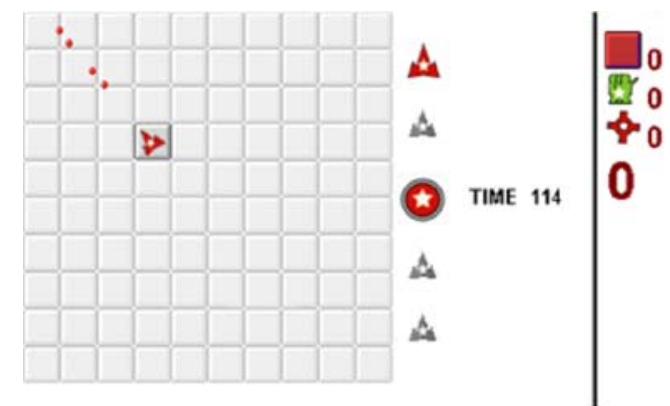

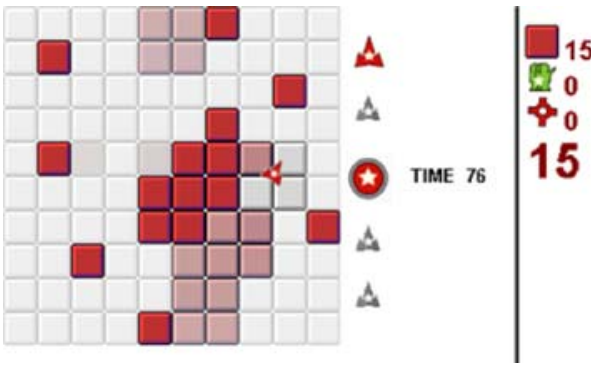

Fig. 3 Image of tile coloring. Passing over tiles within the grid initially highlights the tiles. When a flying pattern is performed successfully, the colored tiles keep their color, but the color disappears again when a pattern is made a second time

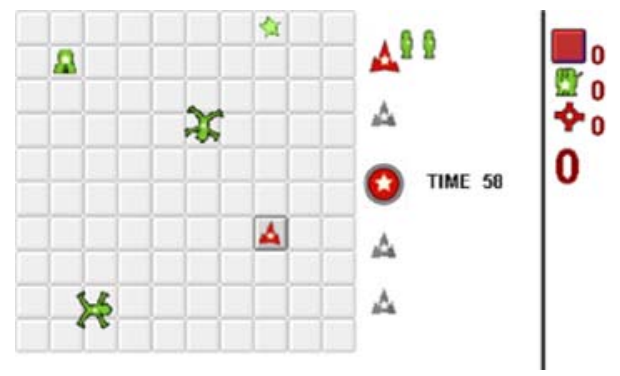

Fig. 4 Image of item collecting. Items appear as figures floating within the playing field. An item is collected when the aircraft is placed above it

movements in terms of direction and speed. At the third level of complexity, a shooting ability was added to the continuous movements described above (Fig. 2).

- Tile coloring involved the possibility of coloring tiles by moving the aircraft above the tiles in specific patterns. When a pattern is made above tiles that are already colored, the colors of these tiles disappeared again. With increased complexity, it became increasingly difficult to plan how and where specific patterns had to be made to color as many tiles as possible. At the first level of complexity, a pattern consisted of a single line. At the second level of complexity, a pattern consisted of either a square or a cross, of which the dimensions increased at the third level of complexity (Fig. 3).

- Item collecting involved the possibility of collecting items that appeared within the game by placing the aircraft above them. Points could be earned by collecting items. Collecting items in different combinations created new possibilities within the game. At each level of complexity a different item was added, thereby increasing the number of combinations that could be made (Fig. 4).

- Multiplay involved the possibility of playing the game together with other players, affecting the number of players physically present as well as the number of virtual avatars. The possibilities for social interaction increased with the complexity. At the first level of complexity, the game was played alone. At the second level of complexity, two players could play against each other, and at the third level of complexity two players teamed up against the experimenter (Fig. 5).

\subsubsection{Experimental design}

The experiment was set up as a full factorial-within subjects-design, in which the total number of game features varied according to (1) the number of game strategies that were combined in the game; and (2) the level of complexity at which these game strategies could be played. The total number of game features was therefore calculated by multiplying the number of game strategies by the level of complexity at which they were set. This resulted in a total of 12 experimental conditions varying in the number of game features (Table 1). The specific game strategies (A-D) that were utilized varied randomly across the experimental conditions.

\subsubsection{Participants}

Ten subjects participated in the experiment. They were either students or employees of the Industrial Design Engineering Department. Their ages ranged from 24 to 28, 
Fig. 5 Image of Multiplay. The aircraft appear in multiple forms in two different colors to distinguish the players. The physical situation is shown at the right

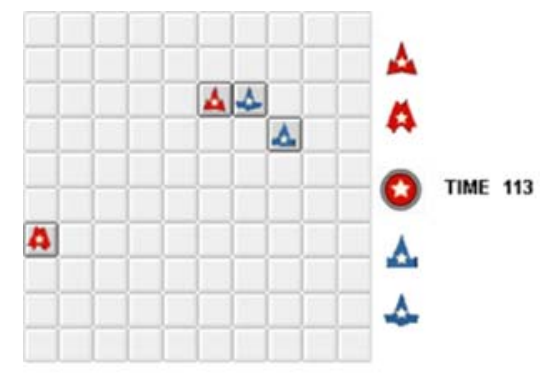

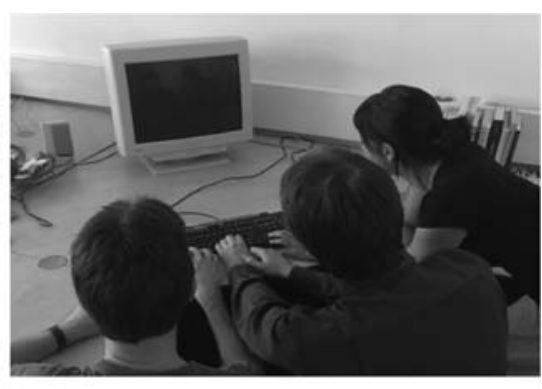

Table 1 Matrix showing the number of game features across the experimental conditions based on the number of game strategies and the level of complexity at which they were set

\section{Number of game strategies}

\begin{tabular}{lc|cccc|}
\multirow{2}{*}{\begin{tabular}{l} 
Level of \\
\cline { 3 - 5 } complexity
\end{tabular}} & 1 & 1 & 2 & 3 & 4 \\
& 2 & 2 & 4 & 6 & 8 \\
& 3 & 3 & 6 & 9 & 12 \\
\hline
\end{tabular}

with an average age of 26 and a standard deviation of 1.3 years. Six participants were male and four were female.

\subsubsection{Procedure}

The participants were asked to play 12 games for a maximum of 2 min per game. The games were played in a room with a desktop computer on a table. A maximum of three people could sit behind the monitor. During the experiment, the experimenter was present and was positioned in such a way that he remained out of sight of the participants. The experimenter only appeared when he was needed as a player in the instance of Multiplay where two participants team up against the experimenter (who controlled two aircraft avatars simultaneously). Participants could stop a playing session at will by pressing the restart button on the screen with a mouse click.

Before the experiment started, the participants played two demonstration games for $30 \mathrm{~s}$. One of these games involved a game setup in which only one feature was available. The other game involved a game setup in which all 12 features were available. Subsequently, the participants played a series of 12 games in a randomized order. After each game, the participants were asked to judge the levels of experienced richness, variety and complexity on a ten-point scale using a pen-and-paper format.

\subsection{Results and discussion}

Increasing the number of game features led to increased levels of experienced richness. Cronbach's alpha was calculated for the three items on the questionnaire, i.e., richness, variety and complexity, as a measure of internal consistency. Alpha measured .928 $(N=120,3$ items $)$, indicating that the three items measured the same construct and that they could be grouped (Carmines and Zeller 1979). Figure 6 denotes the resulting experienced richness scores as a function of the number of game strategies and the level of complexity. It can be observed that as the number of game features increased, the levels of experienced richness increased for both the number of game strategies and the level of complexity at which they were set. Next, an ANOVA-repeated-measures analysis was performed on the grouped item ratings. Significant main effects of the number of game strategies and the level of complexity on experienced richness were found, confirming that by increasing the number of game features the levels of experienced richness increased (Table 2). The significant interaction effect between the number of game strategies and the level of complexity can be attributed mainly to the low variation in richness scores when only one game strategy is involved. Concluding, results show that by increasing the number of game features, the levels of experienced richness increased. However, the extent to which the number of game features contributed to the richness variance for each game strategy separately remained undiscovered, because the game strategies were combined randomly across experimental conditions.

\section{Experiment 2}

The goal of this experiment is to examine the influence of experienced richness of a game and players' expertise on experienced control and engagement in game play.

\subsection{Method}

\subsubsection{Stimuli}

Eight video games varying in levels of experienced richness were selected out of the pool of 12 games used in the previous experiment. The richness levels of these 
Fig. 6 Mean scores of experienced richness as a function of the number of game strategies and the level of complexity. The numbers next to the symbols denote the number of game features determined by multiplying the number of game strategies by the level of complexity

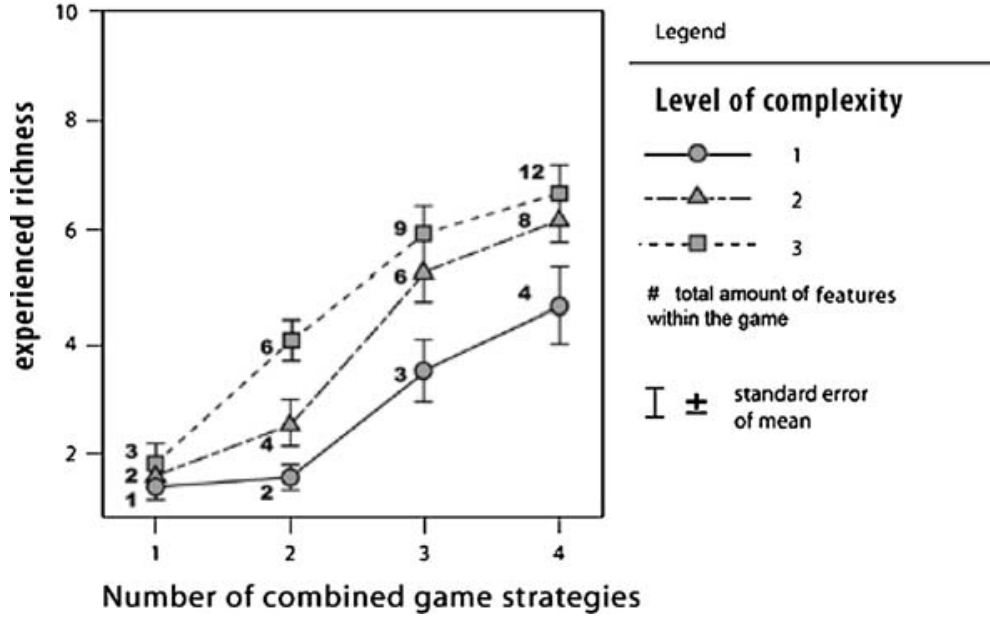

Table 2 ANOVA results of number of game strategies and level of complexity effects on the levels of experienced richness

\begin{tabular}{ll}
\hline Factors & Experienced richness \\
\hline Number of game strategies & $F_{(3,27)}=56.637, p<0.000^{* *}$ \\
Level of complexity & $F_{(2,18)}=18.390, p<0.000^{* *}$ \\
$\begin{array}{l}\text { Number of game strategies } \\
\text { x Level of complexity }\end{array}$ & $F_{(6,54)}=2.429, p<0.038^{*}$ \\
\hline
\end{tabular}

Table 3 Ranking of the 8 games used in this experiment based on the richness scores assessed in experiment 1

\begin{tabular}{lllllllll}
\hline Richness rank & 1 & 2 & 3 & 4 & 5 & 6 & 7 & 8 \\
\hline Richness score & 1.6 & 2.5 & 3.5 & 4.7 & 5.3 & 5.9 & 6.2 & 6.7
\end{tabular}

videogames were distributed about equally over the richness scale. On a scale from 1 to 10 , richness scores varied between 1.6 and 6.7, with a mean experienced richness score of 4.6 and a standard deviation of 2.5 (Table 3 ).

\subsubsection{Experimental design}

The experiment was set up as a between-subjects design with four conditions varying in how games of different richness ranks were presented over time. These conditions were called: Increasing richness, Decreasing richness, High richness and Low richness (Fig. 7). In the Increasing richness and Decreasing richness conditions, participants played a series of 10 games that either increased in richness from rank 1 to 8 in 10 intermediate steps or decreased in richness rank from 8 to 1 in 10 intermediate steps after each successive playing session (richness ranks 4 and 6 were played twice in a row). In the High richness and Low richness conditions, participants repeatedly played a game with richness ranks 1 and 8, respectively. By varying the richness rank and playing session, both the effect of experienced richness and players' expertise on the levels of experienced control and engagement can be assessed.

\subsubsection{Participants}

A total of 25 subjects, 15 male and 10 female, participated in the experiment. The participants were either students or employees of the Industrial Design Engineering Department. Their ages ranged between 19 and 33, with a mean age of 24 and a standard deviation of 3 years. Four subjects participated in the Low richness condition; seven subjects participated in the High richness condition; seven subjects in the Increasing richness condition; and seven subjects in the Decreasing richness condition.

\subsubsection{Procedure and measures}

The participants were told that the experiment was about evaluating the playability of several video games. The games were played in ten sessions over a 3-day period. Within each playing session, the game had to be played within a time period of $10 \mathrm{~min}$, but participants were free to stop earlier. After each playing session, participants evaluated game play by rating 12 items. Each item had to be assessed on a 10-point numerical scale ranging from 1 (left) to 10 (right). The list included items assessing selfconfidence, ease and efficiency (White 1959; Skinner 1996; Ajzen 2002; Hedman and Sharafi 2004), and items assessing the experience of enjoyment, motivation, challenge, excitement, skill development and discovering new possibilities (Malone 1981; Csikszentmihalyi 1990; Webster et al. 1993; Jacques et al. 1995; Laurel 1991; Chapman et al. 1999; Garris 2002). 

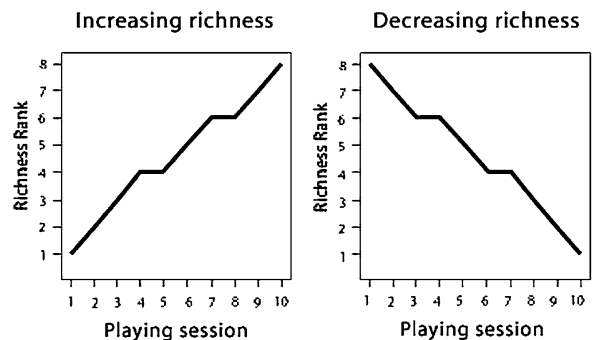

Fig. 7 Schematic overview of the four experimental conditions. In the Increasing richness condition (outer left) and Decreasing richness condition (left), the richness rank either increased or decreased after each successive playing session, while in the High richness condition

Table 4 Results of the principal component analysis with varimax rotation on the items measuring control and engagement

\begin{tabular}{llll}
\hline Item & \multicolumn{3}{l}{ Principal components with varimax rotation } \\
\cline { 2 - 4 } & 1 & 2 & \\
& Engagement & Control & Alpha \\
\hline Challenge & 0.932 & & \\
Excitement & 0.911 & & \\
Engagement & 0.891 & 0.350 & \\
Motivation & 0.861 & 0.401 & \\
Enjoyment & 0.850 & 0.354 & \\
New possibilities & 0.733 & 0.355 & \\
Skill development & 0.718 & 0.504 & \\
Control & & 0.858 & \\
Ease & & 0.840 & \\
Efficiency & 0.477 & 0.773 & \\
Self-confidence & 0.397 & 0.749 & \\
Playability & 0.492 & 0.719 & 0.91 \\
Eigenvalue & 8.268 & 1.449 & \\
\% Variance explained & $68.90 \%$ & $12.08 \%$ & \\
\hline
\end{tabular}

$N=200$. Factor loadings $<0.3$ are omitted

\subsection{Results}

\subsubsection{Scale construction}

A principal component analysis was conducted to determine the components underlying the assessments of the range of questionnaire items. The analysis resulted in the extraction of two components, each with an eigenvalue higher than one together explaining about $81 \%$ of the total variance (Table 4). The two components grouped the items identically as in a previous study in which a different digital game was assessed (Rozendaal et al. 2007a). Following that study, the two components will be labeled engagement and control. For each component a sum scale was developed by averaging the individual items. For the two multi-item scales, Cronbach's alpha was calculated to assess their internal consistency. For the first component,
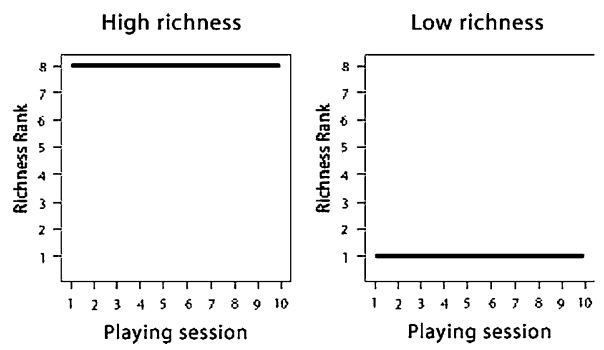

(right) and Low richness condition (outer right), the richness rank remained fixed at a high and low level, respectively, across all playing sessions

assessing engagement, alpha measured $0.97(N=200,7$ items). For the second component, assessing control, alpha measured 0.91 ( $N=200,5$ items). For both components alpha measured above the critical threshold of 0.70 (Carmines and Zeller 1979), indicating that the items reliably assessed two components, namely, experienced engagement and control, respectively.

\subsubsection{Experimental effects on control and engagement}

As a second step, the extent to which the experimental conditions affected the levels of experienced control and engagement was investigated. Figure 8 shows experienced control (left) and engagement (right) as a function of Richness rank for the Increasing richness and Decreasing richness conditions. Judgments for games having Richness rank 4 and 6 that were played twice in a row were grouped by taking the mean score of the two succeeding playing sessions. It can be seen that as Richness rank increased, the levels of experienced control initially increased after which it decreased. Similarly, experienced engagement also increased as Richness rank increased, but eventually leveled off.

Figure 9 denotes experienced control (left) and engagement (right) as a function of playing session for the High richness and Low richness conditions. Looking at the High richness condition, it appears that when the number of playing sessions increased the levels of experienced control initially increased, after which they decreased, and the levels of experienced engagement initially fluctuated at intermediate levels and then also decreased. Looking at the Low richness condition, the levels of experienced control and engagement remained at lower levels during all playing sessions. In this Low richness condition, levels of experienced control and engagement could not be assessed from playing session 7 onwards; participants stopped playing because they were extremely bored by the game that was used. When looking again at Fig. 8, both levels of control and engagement for the game with Richness rank 8 were higher for the Increasing richness condition than for the 

between experienced control (left) and engagement (right) as a function of Richness rank for the Increasing richness and the Decreasing richness conditions
Fig. 8 The relationship
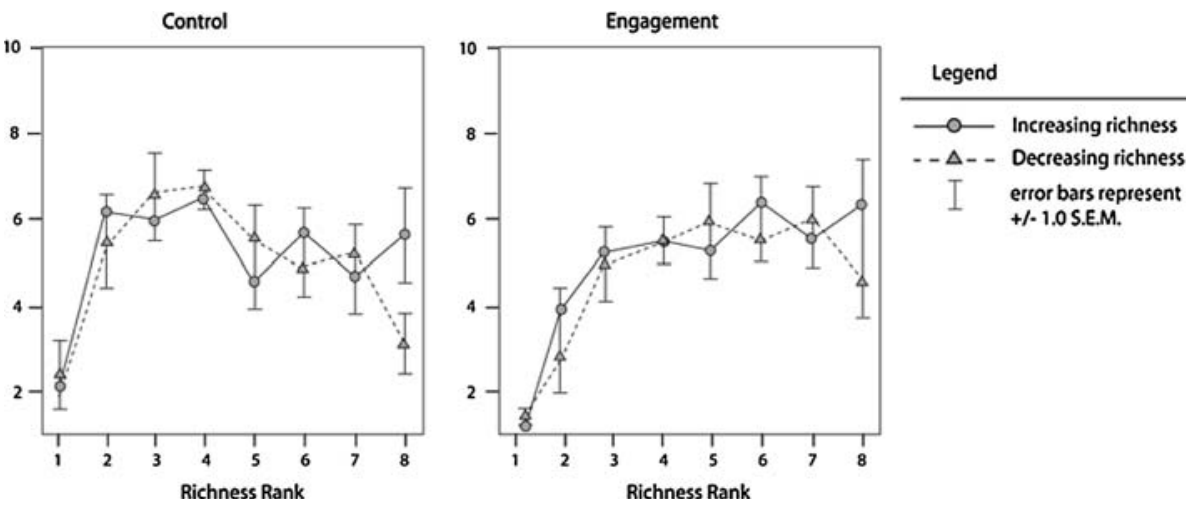

Decreasing richness condition; apparently, players felt more in control of the game and found it more engaging when this game was played last than when it was played first.

\subsubsection{Interrelations between experiential variables}

The last step involved an analysis of the relationship between the experienced richness, control and engagement. Figure 10 shows the levels of experienced richness scores (taken from experiment 1), together with the experienced control and engagement scores as a function of the Richness rank. This figure shows that most engagement scores are positioned between the richness and control scores. When examining the model in which experienced richness and control accumulate into experiences of engagement, a multiplicative model slightly favors an averaging model because of its higher correlation value (.977 vs. 0.972, $N=112)$ and lower error term ( 0.352 vs. $0.386, N=112)$. However, both models are significant $(p<0.000)$.

\subsection{Discussion}

The results suggest that experienced engagement is based on the extent to which the game provided rich experiences as well as the extent to which the player feels in control of the game. Similar observations were found in two previous studies investigating the engagement of video games (van Reekum et al. 2004; Rozendaal et al. 2007a), voicemail

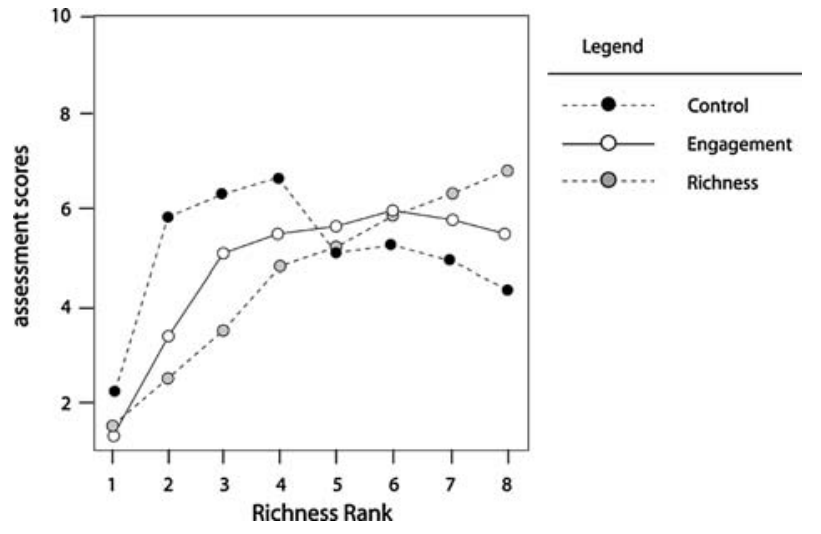

Fig. 10 Mean scores of experienced richness (taken from experiment 1) and experienced control and engagement (taken from the Increasing and Decreasing richness conditions) as a function of Richness rank

browsing (Rozendaal et al. 2008a) and multimedia exploration (de Ridder and Rozendaal 2008). While experienced richness promotes engagement due to the excitement experienced when perceiving a game's potential for developing human faculties, experienced control affects engagement because these potentials can be assimilated by a player. When taking the favored multiplicative model as a starting point, engagement $(E)$ can be calculated by taking the square root of the product of experienced richness $(R)$ and control $(C): E=(R C)^{0.5}$. The level of the experienced engagement is raised when either the level of
Fig. 9 Graphs showing the relationship between experienced control (left) and engagement (right) as a function of playing session for the High richness and Low richness conditions
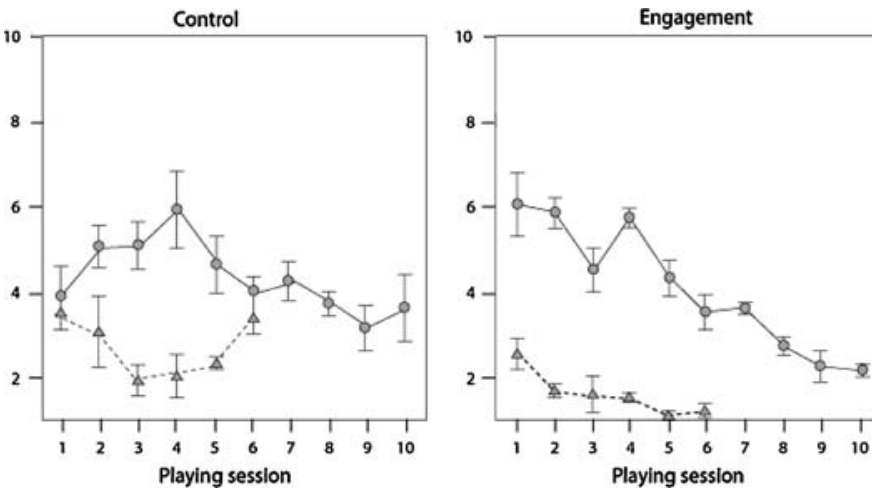

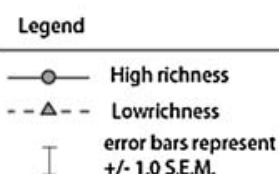


experienced richness or control, or both, are raised. This model can therefore be seen as an articulation of Csikszentmihalyi's theory of Flow (1990).

As in previous studies, the results showed that by increasing the number of game features the levels of experienced richness increased (Steuer 1992; Manninen 2002; Rozendaal et al. 2007b). Games that were experienced as increasingly rich allowed players to alternate between playing strategies, feel challenged behaviorally and/or socially and allowed players to be stimulated sensorially. The results further showed that by increasing the number of game features, experienced control initially increased after which it decreased. This may be interpreted as a combined effect of decisional and cognitive control (Averill 1973). Increasing the number of game features may have increased the choices available to players, thereby increasing their decisional control. At the same time, the increased number of game features resulting in increased visual clutter and noise within the appearance of the game may have decreased cognitive control, since the various playing strategies were difficult to distinguish without training; obstructing play as a consequence. A parallel can be drawn between this finding and the phenomenon of choice and crowding in service environments (Hui and Bateson 1991). For instance, giving people the choice of remaining in or leaving a bank environment correlated positively with perceived control, while crowding within a bank environment correlated negatively with perceived control since costumer density obstructed costumers' behavior.

As expected, experienced control was found to increase in time since players learned to utilize the available game strategies in game play (VanDeventer and White 2002). Counter-intuitively, experienced control eventually started to decrease over time. This may be the result of feelings of apathy described in relation to Flow theory (Ellis et al. 1994). Apathy may have been experienced when players were asked to continue playing even when they were bored by the game. As a result, players may actually stop playing, as was observed for the Low richness condition. Further, the assumption that the levels of experienced richness decrease over time could not be directly assessed in this study. However, as their expertise increased players attuned to different aspects of the game, possibly having influenced levels of experienced richness due to a shift of attentional focus (Wickens 1992); experienced richness may decrease when game features that were initially perceived as distinct qualities combine into higher-order gestalts as players' expertise increases (Lindley and Sennersten 2006). However, based on the same principle certain game features may be revealed that went unnoticed earlier, thereby possibly raising the levels of experienced richness.

It could not be assessed in this experiment to what extent functional, manipulation and appearance features, as well as features related to shared access, may have influenced experienced control and engagement differently. As in the previous discussion on richness, the question can be asked how different game features may affect the various forms of perceived control differently (Averill 1973; Skinner 1996), and whether there are variations in experiencing mental, behavioral, sensorial and social forms of engagement as a result. When investigating these facets in more detail, the results may indicate that richness, control and engagement are not one-dimensional constructs but may involve multiple factors depending on which game features are varied. A similar phenomenon was observed in relation to the Flow experience when it was investigated under varying usage situations (Novak et al. 2003).

\section{Conclusions}

The results of this study nicely illustrate the interplay between game features and players' expertise on engagement mediated by experienced richness and control. Results have shown that engaging game play can be created by increasing the number of game features to such an extent that game play is experienced as rich while still allowing players a sense of control. Given that players' expertise increases over time, game features should be variable to maintain optimal levels of engagement. However, it still remains unclear exactly how richness is affected over time. By combining an experimental approach with a design approach, the findings of this study may contribute to the discussion on user experience and could also be of practical value in game design. However, investigating interactions in other (gaming) contexts would greatly strengthen this knowledge. Also, the range of possible factors, including social ones, should be examined in more detail. New studies are being set up in which these issues are further explored.

Acknowledgments This study was carried out as part of the research program of the ICT-Delft Research Centre. Thanks to Anneke Nipius and Rosalind Boschloo for their help in developing the concept of richness. Thanks to the reviewers for their useful and constructive comments, and thanks to the ID-Studiolab members for their input and inspiration.

Open Access This article is distributed under the terms of the Creative Commons Attribution Noncommercial License which permits any noncommercial use, distribution, and reproduction in any medium, provided the original author(s) and source are credited.

\section{References}

Ajzen I (2002) Perceived behavioural control, self-efficacy, locus of control, and the theory of planned behavior. J Appl Soc Psychol $32: 665-683$ 
Averill JR (1973) Personal control over aversive stimuli and its, relationship to stress. Psychol Bull 80(4):286-303

Barfield L, van Burgsteden W, Lanfermeijer R, Mulder B, Ossewold J, Rijken D, Wegner P (1994) Interaction design at the Utrecht school of the arts. SIGCHI Bull 26(3):49-86

Björk S, Lundgren S, Holopainen J (2003) Game design patterns. In: Proceedings of level up-1st international digital games research conference 2003, Utrecht, The Netherlands

Bradshaw JM (1997) An introduction to software agents. In: Bradshaw JM (ed) Software agents. The MIT Press, Cambridge

Carmines EG, Zeller RA (1979) Reliability and validity assessment. Sage, Newbury Park

Chapman P, Selvarajah S, Webster J (1999) Engagement in multimedia training systems. HICSS-32 proceedings of the 32nd annual Hawaii international conference on system sciences, CD-ROM. IEEE, Maui

Chen H, Wigand RT, Nilan MS (1999) Optimal experience of web activities. Comput Hum Behav 15:585-608

Csikszentmihalyi M (1990) Flow: the psychology of the optimal experience. HarperCollins, New York

Deci EL, Ryan RM (2000) Self-determination theory and the facilitation of intrinsic motivation, social development, and well-being. Am Psychol 55(1):68-78

Djajadiningrat JP, Wensveen SAG, Frens JW, Overbeeke CJ (2004) Tangible products: redressing the balance between appearance and action. Pers Ubiquit Comput 8(5):294-309

Douglas JY, Hargadon A (2001) The pleasures of immersion and engagement: schemas, scripts and the fifth business. Digital Creativity 12(3):153-166

Dreyfus HL, Dreyfus SE, Athanasiou T (1986) Mind over machine: the power of human intuition and expertise in the era of the computer. The Free Press, New York

Ellis GD, Voelkl JE, Morris C (1994) Measurement and analysis issues with explanation of variance in daily experience using the flow model. J Leis Res 26(4):337-356

Fiske DW, Maddi SR (1961) Functions of varied experience. Dorsey Press, Homewood

Garris R, Ahlers R, Driskell JE (2002) Games, motivation, and learning: a research and practice model. Simul Gaming 33:441467

Gaver W (1996) Affordances for interaction: the social is the material for design. Ecol Psychol 8(2):111-129

Grünvogel SM (2005) Formal models and game design. Game Studies 5(1). http://www.gamestudies.org

Hedman L, Sharafi P (2004) Early use of internet-based educational resources: effects on students' engagement modes and flow experience. Behav Inform Technol 23(2):137-146

Hodges BH, Baron RM (2007) On making social psychology more ecological and ecological psychology more social. Ecol Psychol 19(2):79-84

Hornbæk K (2006) Current practice in measuring usability: challenges to usability studies and research. Int J Hum Comput Stud 64(2):79-102

Hui MK, Bateson JEG (1991) Perceived control and the, effects of crowding and consumer choice on the service experience. J Consum Res 18:174-184

Jacques R, Preece J, Carey T (1995) Engagement as a design concept for multimedia. Can J Educ Commun 24(1):49-59

Järvinen A, Heliö S, Mäyrä F (2002) Communication and community in digital entertainment services. Pre-study research report. Hypermedia Laboratory Net Series 2, p 17. Retrieved 10 January 2008 from http://tampub.uta.fi/tup/951-44-5432-4.pdf

Keyson DV (2008) The experience of intelligent products. In: Schifferstein HNJ, Hekkert P (ed) Product experience. Elsevier science, Amsterdam
Kirriemuir J (2002) Video gaming, education and digital learning technologies. D-Lib Magazine. Retrieved 10 January 2008 from http://www.dlib.org/dlib/february02/kirriemuir/02kirriemuir. html

Klabbers JHG (2006) A framework for artifact assessment and theory testing. Simul Gaming 37(2):155-173

Klastrup L (2003) "You can't help shouting and yelling': Fun and Social Interaction in Super Monkey Ball". In: Copier, Marinka, Raessens, Joost (ed) Proceedings from level up-digital games research conference, November 2003. University of Utrecht Press, Utrecht

Kreijns K, Kirschner PA, Jochems W, van Buuren H (2007) Measuring perceived sociability of computer supported collaborative learning environments. Comput Educ 49:176-192

Laurel B (1991) Computers as theatre. Addison-Wesly, Reading

Lindley CA (2004) Ludic engagement and immersion as a generic paradigm for human-computer interaction design. Proceedings of ICEC 2004, Eindhoven, The Netherlands, pp 2-13

Lindley CA, Sennersten CC (2006) A cognitive framework for the analysis of game play: tasks, schemas and attention theory. Workshop on the cognitive science of games and game play, the 28th annual conference of the cognitive science society, 26-29 July, Vancouver, Canada

Ludvigsen M (2006) Designing for social interaction. Department of Design. Aarhus School of Architecture

Malone TW (1981) Toward a theory of intrinsically motivating instruction. Cognitive Sci 4:333-369

Manninen T (2002) Contextual virtual interaction as part of ubiquitous game design and development. Pers Ubiquit Comput 6(6):390-406

Maslow AH (1970) Motivation and personality. Harper and Row, New York

Novak TP, Hoffman DL, Yung YF (2000) Measuring the customer experience in on-line environments: a structural modeling approach. Mark Sci 19(1):22-42

Novak TP, Hoffman DL, Duhachek A (2003) The influence of goaldirected and experiential activities on online flow experiences. $\mathrm{J}$ Consumer Psychol 13(1\&2):3-16

Pirhonen A (1998) Analysis of the concept of redundancy concerning the design of multimodal combinations of output-elements. Proceedings of the APCHI'98 3rd asian pacific computer human interaction. IEEE, Los Alamitos, pp 273-278

Rasmussen J (1983) Skills, rules, and knowledge: signals, signs, and symbols, and other distinctions in human performance models, IEEE Transactions on Systems. Man Cybern 13:257-266

Ridder de H, Rozendaal MC (2008) Beyond image quality: designing engaging interactions with digital products. 20th Conference on Human Vision and Electronic Imaging, Proceedings of SPIE Vol. 6806, San Jose, USA

Rogers C (1951) Client centered therapy. Houghton Mifflin, Boston

Rozendaal MC Keyson DV, Ridder H de (2007a) Product behavior and appearance effects on experienced engagement during experiential and goal-directed tasks. International conference on designing pleasurable products and interfaces. Helsinki, Finland, pp 181-194

Rozendaal MC, Keyson DV, Ridder H de (2007b) Interactivity, vividness and richness in user interfaces. The 6th international workshop on social intelligence design. Trento, Italy, pp 269 278

Rozendaal MC, Braat BAL, Wensveen SAG (2008a) Exploring sociality and engagement in gameplay through interdependence. The 7th international workshop on social intelligence design. San Juan, Puerto Rico

Rozendaal MC, Keyson DV, Ridder de H (2008b) Product features and task effects on experienced richness, control and engagement 
during voice mail browsing. Pers Ubiquit Comput doi: 10.1007/s00779-008-0201-8

Schwartz B (2000) Self-determination: the tyranny of freedom. Am Psychol 55(1):79-88

Skinner EA (1996) A guide to constructs of control. J Pers Soc Pers Psychol 71:549-570

Stangor C (2004) Social groups in action and interaction. Psychology Press, New York

Steuer J (1992) Defining virtual reality: dimensions determining telepresence. J Commun 42(2):73-93

Sutcliffe A (2002) Multimedia user interface design. In: Jacko J, Sears A (eds) The human-computer interaction handbook: fundamentals, evolving technologies, and emerging applications. Lawrence Erlbaum and Associates, Mahwah, NJ, pp 245-262

Ullmer B, Ishii H (2000) Emerging frameworks for tangible user interfaces. IBM Syst J 39(3\&4):915-931

van Reekum CM, Johnstone T, Banse R, Etter A, Wehrle T, Scherer KR (2004) Psychophysiological responses to appraisal dimensions in a computer game. Cogn Emot 18(5):663-688
VanDeventer S, White J (2002) Expert behaviour in children's video game play. Simul Gaming 33(1):28-48

Volet S, Wosnitza M (2004) Social affordances and students' engagement in cross-national online learning: an exploratory study. J Res Int Educ 3(1):5-30

Webster J, Ho H (1997) Engagement in multimedia training systems. Proceedings of the 32th Hawaii international conference on system sciences. IEEE

Webster J, Trevino LK, Ryan L (1993) The dimensionality and correlates of flow in human-computer interactions. Comput Hum Behav 9:411-426

White RW (1959) Motivation reconsidered: the concept of competence. Psychol Rev 66:297-335

Wickens CD (1992) Engineering psychology and human performance. Harper Collins, New York 